\title{
UMA CONCEPÇÃO KANTIANA DE IGUALDADE
}

\author{
John Rawls
}

\section{I}

Meu propósito nestas observações é fazer um breve registro da concepção de igualdade que subjaz à visão exposta em Uma Teoria da Justiça e os princípios ali considerados. Espero enunciar a idéia intuitiva fundamental de maneira simples e informal, sem nenhum esforço, portanto, de esboçar o argumento a partir da posição original. ${ }^{1} \mathrm{Na}$ verdade, esta construção só é mencionada no final, e apenas para indicar o seu papel em fornecer uma interpretação kantiana para a concepção de igualdade já apresentada.

Uma vez plenamente articulada, qualquer concepção de justiça exprime uma concepção de pessoa, das relações entre pessoas e da estrutura geral e fins da cooperação social. Aceitar os princípios que representam uma concepção de justiça equivale a aceitar um ideal de pessoa; e, ao agir a partir desses princípios, nós realizamos tal ideal. Comecemos, então, com uma tentativa de descrever o tipo de pessoa que nós podíamos ser e a forma de sociedade na qual nós gostaríamos de viver e de formar nossos interesses e caráter. Chegamos desse modo à noção de uma sociedade bem-ordenada. Primeiramente descreverei essa noção e em seguida a usarei para explicar uma concepção kantiana de igualdade.

Antes de mais nada, uma sociedade bem-ordenada é efetivamente regulada por um conceito público de justiça. Ou seja, é uma sociedade na qual todos os membros aceitam e sabem que os outros aceitam os mesmos princípios (a mesma

Tradução de Nythamar de Oliveira. Versão original: John Rawls, "A Kantian Conception of Equality" (1975). In Collected Papers, ed. Samuel Freeman, Harvard University Press, 2001, p. 254-266.

O argumento em Uma Teoria da Justiça (Cambridge, Mass.: Harvard University Press, 1971) foi igualmente informal na medida em que defendia os princípios de justiça pela consideração do equilíbrio de razões a seu favor dada uma breve lista de concepções filosóficas tradicionais. Parece, todavia, que os argumentos formais sejam possíveis. Steven Strasnick encontrou uma prova de que certas condições familiares sobre funções da escolha social (que parece natural associá-las com a posição original), quando reunidas com o princípio de prioridade preferencial, acarretam no princípio da diferença. Ele também mostrou que se segue uma forma do princípio da diferença, se for modificada a condição de independência de Arrow (usada na prova do teorema da impossibilidade) para acomodar a noção de prioridade de preferência.

\begin{tabular}{|l|l|l|l|l|l|}
\hline VERITAS & Porto Alegre & v. 52 & n. 1 & Março 2007 & p. 108-119 \\
\hline
\end{tabular}


concepção) de justiça. O que ocorre é que as instituições sociais básicas e seus arranjos num esquema único (a estrutura básica) realmente satisfazem e estão embasados em boas razões que todos crêem satisfazerem tais princípios. Finalmente, a publicidade também implica que a concepção pública está fundamentada em crenças razoáveis que tenham sido estabelecidas por métodos de investigação geralmente aceitos; e o mesmo é verdade quanto à aplicação de tais princípios aos arranjos sociais básicos. Este último aspecto da publicidade não significa que todos compartilhem as mesmas crenças religiosas, morais e teóricas; ao contrário, pressupõe-se que estas sejam acentuadas e que haja na verdade diferenças irreconciliáveis sobre tais questões. Mas, ao mesmo tempo, há um entendimento compartilhado de que os princípios de justiça e sua aplicação à estrutura básica da sociedade deviam ser determinados por considerações e evidência apoiadas por procedimentos racionais comumente reconhecidos.

Em segundo lugar, eu suponho que os membros de uma sociedade bemordenada são, eles mesmos, pessoas morais livres e iguais. Eles são pessoas morais, na medida em que, uma vez alcançada a idade da razão, cada um tem e vê os outros como tendo um senso realizado de justiça; e este sentimento informa a sua conduta para a maior parte do tempo. Que eles sejam iguais é expresso pela suposição que cada um deles tem e se vêem mutuamente como possuindo um direito ao respeito igual e consideração em determinar os princípios pelos quais os arranjos básicos da sociedade devem ser regulados. Finalmente, exprimimos o fato de serem livres ao estipular que cada um deles tem e se vêem mutuamente como possuindo propósitos fundamentais e interesses de ordem superior (uma concepção do seu bem) em nome dos quais é legítimo fazer reivindicações mútuas quanto ao desígnio de suas instituições. Ao mesmo tempo, enquanto pessoas livres, eles não pensam de si mesmos como inevitavelmente vinculados, ou como idênticos com a busca de qualquer arranjo particular de interesses fundamentais que eles possam ter num momento qualquer; pelo contrário, eles se concebem a si mesmos como capazes de revisar e alterar esses fins terminais e dão prioridade à preservação da sua liberdade nesse sentido.

Ademais, estou assumindo que a sociedade bem-ordenada é estável com relação à sua concepção de justiça. Isso significa que instituições sociais engendram um sentido efetivo sustentável de justiça. Ao considerar a sociedade como uma preocupação vigente, os seus membros adquirem, à medida que crescem, uma adesão à concepção pública e tal compromisso freqüentemente supera as tentações e desgastes da vida social.

Ora, o que nos interessa aqui é uma concepção de justiça e a idéia de igualdade que lhe é correlata. Assim, suponhamos que uma sociedade bem-ordenada exista nas circunstâncias da justiça. Estas requerem uma certa concepção de justiça e dão destaque ao seu papel especial. Em primeiro lugar, há uma escassez moderada. Isso significa que, embora a cooperação social seja produtiva e mutuamente vantajosa, o ganho de uma pessoa ou grupos não implica necessaria- 
mente a perda de outrem, os recursos naturais e o desenvolvimento tecnológico são tais que os frutos de esforços conjuntos ficam aquém das reivindicações que as pessoas fazem. Em segundo lugar, pessoas e associações têm concepções contrárias do bem que as levam a fazer reivindicações conflitantes umas sobre as outras; e também sustentam convicções religiosas, filosóficas e morais opostas (sobre questões que a concepção pública deixa abertas) assim como os diferentes modos de avaliar argumentos e evidência em muitos casos importantes. Dadas tais circunstâncias, os membros de uma sociedade bem ordenada não são indiferentes quanto ao modo como os benefícios produzidos pela sua cooperação são distribuídos. Um conjunto de princípios é requerido para arbitrar entre arranjos sociais que dêem forma a essa divisão de vantagens. Assim, o papel dos princípios de justiça é atribuir direitos e deveres na estrutura básica da sociedade e especificar a maneira pela qual as instituições devem influenciar a distribuição geral dos retornos da cooperação social. A estrutura básica é o objeto primário da justiça e aquele ao qual os princípios de justiça são aplicados em primeira instância.

Talvez seja útil observar que a noção de uma sociedade bem-ordenada é uma extensão da idéia de tolerância religiosa. Considere uma sociedade pluralista, dividida através de suas linhas religiosas, étnicas ou culturais, nas quais os diversos grupos têm alcançado um firme entendimento sobre o esquema de princípios, para regular suas instituições fundamentais. Embora tenham divergências profundas quanto a outras coisas, há um acordo público quanto a esse referencial de princípios e os cidadãos se vinculam. Uma sociedade bem-ordenada não tem atingido harmonia social em todas as coisas, se na verdade isso fosse desejável; mas ela tem logrado uma grande medida de justiça e estabelecido uma base para a amizade cívica, o que torna possível assegurar a associação conjunta de pessoas.

\section{II}

A noção de uma sociedade bem-ordenada assume que a estrutura básica, as instituições sociais fundamentais e seus arranjos em um esquema único são o objeto primário de justiça. Qual é a razão para tal pressuposto? Antes de mais nada, qualquer discussão acerca da justiça social deve levar em consideração a natureza da estrutura básica. Suponha que comecemos com a idéia inicialmente atraente de que o processo social devesse se desenvolver ao longo do tempo, na medida em que se exigisse que se chegasse eqüitativamente a acordos livres e que estes fossem plenamente honrados. Imediatamente precisamos de um registro de quando os acordos são livres e as condições sob as quais eles são alcançados são eqüitativas. Ademais, embora tais condições possam ser satisfeitas num período mais curto, os resultados acumulados de acordos em conjunção com contingências sociais e históricas provavelmente mudariam instituições e oportunidades de tal forma que as condições para acordos livres e eqüitativos não se sustentem mais. A estrutura básica especifica condições de fundo sob as quais as ações de indivíduos, grupos e associações acontecem. A menos que essa estrutura seja 
regulada e corrigida de forma a ser justa através do tempo, o processo social com os seus procedimentos e resultados não é mais justo, embora transações particulares possam parecer livres e eqüitativas, quando vistas por si mesmas. Nós reconhecemos esse princípio, quando dizemos que a distribuição resultante de transações voluntárias de mercado não serão em geral eqüitativas a não ser que uma distribuição prévia de proventos e riquezas e a estrutura do mercado sejam eqüitativas. Assim parecemos forçados a iniciar com um registro de uma estrutura básica justa. É como se o acordo mais importante fosse o que estabelece os princípios que governam essa estrutura. Ademais, esses princípios devem ser reconhecidos previamente, por assim dizer. Concordar com eles agora, quando todos conhecem a sua presente situação, capacitaria alguns para que pudessem tirar vantagem injustamente das contingências sociais e naturais, e dos resultados de acidentes e acúmulos históricos.

Outras considerações também apóiam que se tome a estrutura básica como o objeto primário da justiça. Tem sido sempre reconhecido que o sistema social forma os desejos e aspirações de seus membros; ele determina, em grande proporção, o tipo de pessoas que elas querem ser assim como o tipo de pessoas que são. Assim, um sistema econômico é não apenas um dispositivo institucional para satisfazer carências e desejos existentes (existing wants and desires) mas uma maneira de forjar carências e desejos no futuro. Através de quais princípios devemos regular um esquema de instituições que tenha tais conseqüências fundamentais para nossa concepção de nós mesmos e de nossos interesses e alvos? Essa questão torna-se ainda mais crucial quando, consideramos que a estrutura básica contém desigualdades sociais e econômicas. Estou assumindo que estas sejam necessárias, ou altamente vantajosas, por várias razões: elas são requeridas, a fim de manter e efetivar arranjos sociais, ou para servir como incentivos; ou talvez elas sejam um modo de colocar recursos nas mãos daqueles que podem fazer o melhor uso social dos mesmos; e assim por diante. Em todo caso, dadas essas desigualdades, os projetos de vida dos indivíduos estão destinados a serem afetados de maneira importante pelas suas origens de família e classe, pelos seus dotes naturais e contingências aleatórias de seu desenvolvimento (particular precoce), e por outros acidentes, ao longo do curso das suas vidas. A estrutura social limita, portanto, as ambições e expectativas sociais de diferentes maneiras, pois as pessoas verão a si mesmas com razão em parte de acordo com o seu lugar na estrutura e levarão em conta os meios e oportunidades que elas podem esperar realisticamente.

A justiça da estrutura básica é, portanto, de importância fundamental. O primeiro problema da justiça é determinar os princípios para regular as desigualdades e ajustar os efeitos profundos e de longa duração das contingências sociais, naturais e históricas, particularmente porque essas contingências combinadas com as desigualdades engendram tendências que, quando abandonadas a si mesmas, são profundamente díspares com relação à liberdade e igualdade apropriadas para uma sociedade bem-ordenada. Em vista do papel especial da estrutura básica, não 
podemos assumir que os princípios a ela adequados sejam aplicações naturais, ou mesmo extensões, dos princípios familiares que governam as ações de indivíduos e associações na vida cotidiana que ocorrem dentro do seu âmbito. É mais provável que tenhamos de relativizar a nossa perspectiva ordinária e adotar um ponto de vista mais abrangente.

\section{III}

Enunciarei agora e explicarei os dois princípios de justiça, e discutirei, em seguida, a pertinência desses princípios para uma sociedade bem-ordenada. Eles rezam como se segue:

1. Cada pessoa tem um direito igual ao mais extensivo esquema de liberdades fundamentais iguais compatíveis com um esquema semelhante de liberdades para todos.

2. As desigualdades sociais e econômicas devem satisfazer duas condições: elas devem ser (a) para o maior benefício esperado dos menos favorecidos; e (b) vinculadas a cargos e posições abertas a todos em condições de oportunidade eqüitativa.

O primeiro desses princípios deve ter prioridade sobre o segundo; e a medida de benefício para os menos favorecidos é especificada em termos de um índice de bens primários sociais. Defino esses bens, grosso modo, como direitos, liberdades e oportunidades, proventos e riquezas, assim como as bases sociais de autorespeito (self-respect). Assume-se que os indivíduos querem esses bens independentemente de tudo o mais que queiram ou de quaisquer que sejam os seus fins terminais. Os menos favorecidos são definidos, grosso modo, como a sobreposição (overlap) entre aqueles que são os menos favorecidos por cada um dos três modos de contingências. Assim, esse grupo inclui pessoas cujas origens de família e classe são mais desvantajosas que outras, cujos dotes naturais lhes permitiram ser menos sucedidos e cuja sina e sorte têm sido relativamente menos favoráveis, tudo isso dentro de um alcance normal (como assinalado abaixo) e com as medidas relevantes embasadas nos bens primários sociais. Sem dúvida, várias distinções são necessárias, mas esta definição dos menos favorecidos adequadamente exprime a relação com o problema da contingência e deveria ser suficiente para os nossos propósitos aqui.

Estou também supondo aqui que todo mundo tem necessidades físicas e capacidades psicológicas dentro do alcance normal, de tal modo que os problemas do cuidado médico especial e de como tratar os deficientes mentais não são levantados. Além de prematuramente introduzir questões difíceis, que podem levarnos para além da teoria da justiça, a consideração desses casos complexos pode distrair nossa percepção moral, levando-nos a pensar em pessoas distantes de nós, cujo destino suscita piedade e ansiedade. Embora o primeiro problema da justiça diga respeito às relações entre aqueles que, no curso normal das coisas, 
são participantes plenos e ativos na sociedade e direta ou indiretamente se associam ao longo de toda a sua vida.

Ora, os membros de uma sociedade bem-ordenada são livres e iguais; portanto, consideremos primeiro a pertinência dos dois princípios para a sua liberdade, e, em seguida, para a sua igualdade. Esses princípios refletem dois aspectos da sua liberdade, a saber, liberdade e responsabilidade, que abordarei em seguida. No que tange à liberdade, lembremos que as pessoas numa sociedade bem ordenada se concebem como tendo alvos e interesses fundamentais que elas devem proteger, dentro do possível. É parcialmente em nome desses interesses que elas têm um direito à consideração e respeito iguais no desígnio da sua sociedade. Um exemplo familiar histórico é o interesse religioso; um outro exemplo é o interesse na integridade da pessoa, livre de opressão psicológica e de agressão física. A noção de sociedade bem-ordenada deixa em aberto que expressão particular desses interesses ela toma; apenas a sua forma geral é especificada. Mas os indivíduos têm efetivamente interesses dos tipos requeridos, e as liberdades fundamentais necessárias para a sua proteção são garantidas pelo primeiro princípio.

É essencial observar que essas liberdades são dadas por uma lista de liberdades; importantes entre as quais encontram-se a liberdade de pensamento e a liberdade de consciência, a liberdade da pessoa e a liberdade política. Essas liberdades têm um âmbito central de aplicação dentro do qual elas podem ser limitadas e comprometidas apenas quando entram em conflito com outras liberdades fundamentais. Visto que elas podem ser limitadas, quando conflitam entre si, nenhuma dessas liberdades é absoluta; todavia, embora sejam ajustadas para formar um sistema, tal sistema deve ser o mesmo para todos. É difícil - e talvez seja impossível - dar uma definição completa dessas liberdades independentemente de suas circunstâncias particulares, sociais, econômicas e tecnológicas, de uma sociedade bem-ordenada dada. Todavia, a hipótese é que a forma geral de tal lista poderia ser concebida com suficiente precisão a fim de sustentar essa concepção de justiça. Naturalmente, as liberdades que não constam da lista, por exemplo, o direito de possuir certos tipos de propriedade (por exemplo, meios de produção) e liberdade de contrato como entendida pela doutrina do laissez-faire, não são fundamentais; e por isso elas não estão protegidas pela prioridade do primeiro princípio. ${ }^{2}$

Uma razão, portanto, para manter os dois princípios adequados para uma sociedade bem ordenada é que eles asseguram a proteção dos interesses fundamentais que membros de tal sociedade supostamente possuem. Razões adicionais para essa conclusão podem ser dadas pela descrição mais detalhada da noção de uma pessoa livre. Podemos dessa forma supor que tais pessoas se considerem como portadoras de um interesse de ordem superior no modo como todos os seus

Este parágrafo confirma a interpretação de H. L. A. Hart. Ver a sua discussão acerca da liberdade e sua prioridade, Chicago Law Review, 40 (abril 1973): p. 536-540. 
demais interesses, inclusive até mesmo os fundamentais, são formados e regulados por instituições sociais. Como observei acima, as pessoas não se concebem como se fossem inevitavelmente vinculadas a qualquer arranjo particular de interesses fundamentais; ao contrário, elas se percebem como capazes de rever e modificar esses fins terminais. Elas desejam, portanto, dar prioridade a sua liberdade para fazer isso, e assim sua lealdade original e contínua devoção aos seus fins devem ser formadas e afirmadas sob condições que são livres. Ou, para dizer em outros termos, os membros de uma sociedade bem ordenada são vistos como responsáveis pelos seus interesses e fins fundamentais. Embora, enquanto membros de associações particulares, alguns possam decidir na prática delegar essa responsabilidade para outros, a estrutura básica não pode ser construída de forma a prevenir que as pessoas desenvolvam sua capacidade de serem responsáveis ou que obstruam seu exercício da mesma uma vez a tenham alcançado. Os arranjos sociais devem respeitar a sua autonomia e esta aponta para a propriedade dos dois princípios.

\section{IV}

Essas últimas observações sobre a responsabilidade podem ser mais elaboradas em conexão com o papel dos bens primários sociais. Como já foi dito, pode-se supor que as pessoas numa sociedade bem-ordenada queiram tais bens, independentemente de seus fins terminais. E os dois princípios avaliam a estrutura básica em termos de alguns desses bens: direitos, liberdades e oportunidades, proventos e riqueza, e as bases sociais do auto-respeito. Esses últimos são características da estrutura básica que pode ser razoavelmente esperada para afetar o auto-respeito (self-respect) e a auto-estima (self-esteem) (que não são a mesma coisa) em importantes maneiras. ${ }^{3}$ A parte (a) do segundo princípio (o princípio da diferença, ou como os economistas preferem dizer, o critério maximin) usa um índice desses bens para determinar os menos favorecidos. Ora, certamente há dificuldades em obter um índice satisfatório, mas deixarei isso de lado. Dois pontos são particularmente relevantes aqui: primeiro, os bens primários sociais são certas características objetivas de instituições sociais e da situação de pessoas com relação a elas; e segundo, o mesmo índice desses bens é usado para comparar as circunstâncias sociais de cada um. Assim, é claro que, embora o índice forneça uma base para comparações interpessoais para o propósito de justiça, não é uma medida da satisfação ou insatisfação completa de indivíduos. Naturalmente, os pesos precisos adotados em tal índice não podem ser estipulados antecipadamente, pois estes deveriam ser ajustados, ao menos até um certo grau, em vista das condições sociais. O que pode ser colocado inicialmente são certos limites (constraints) nesses pesos, como ilustra a prioridade do primeiro princípio.

Eu abordo os problemas da interpretação do relato dos bens primários no capítulo 14 [dos Collected Papers]. 
Ora, que a responsabilidade de pessoas livres é implícita no uso de bens primários pode ser visto da seguinte maneira. Estamos assumindo que as pessoas são capazes de controlar e rever seus desejos e necessidades à luz de circunstâncias e que elas devem ter responsabilidade ao fazê-lo, visto que os princípios de justiça são realizados, como o são em uma sociedade bem-ordenada. As pessoas não assumem que seus desejos e necessidades são determinados por eventos além de seu controle. Nós não somos, por assim dizer, tomados de sobressalto por eles, como somos talvez por doenças e enfermidades de forma a reivindicar medicamentos e tratamento.

Obviamente, não está sendo sugerido que as pessoas devam modificar seus desejos e fins, quaisquer que sejam as suas circunstâncias. A doutrina dos bens primários não demanda virtudes estóicas. A sociedade, por sua vez, carrega a responsabilidade de sustentar os princípios de justiça e assegura para cada pessoa uma partilha eqüitativa de bens primários (como determinado pelo princípio da diferença) dentro de um contexto de igual liberdade e igualdade eqüitativa de oportunidade. É dentro dos limites dessa divisão de responsabilidade que se espera de indivíduos e associações que formem e moderem seus alvos e aspirações. Assim, entre os membros de uma sociedade bem-ordenada há um entendimento que enquanto cidadãos eles vão reivindicar apenas certos tipos de coisas, como o permitem os princípios de justiça. Convicções passionais e aspirações zelosas não permitem, como tais, que alguém faça reivindicações de recursos sociais ou o desígnio de instituições sociais. Para os propósitos da justiça, a base apropriada de comparações interpessoais é o índice de bens primários e não a força do sentimento ou a intensidade de desejo. A teoria dos bens primários é uma extensão da noção de necessidades, que são distintas de aspirações e desejos. Alguém poderia dizer, então, que os cidadãos e membros de uma sociedade bem-ordenada assumem coletivamente responsabilidade de se tratar mutuamente com justiça [responsibility for dealing justly with one another], embasados numa medida pública e objetiva de necessidades (estendidas), enquanto que, como indivíduos e membros de associações eles, assumem responsabilidade por suas preferências e compromissos [devotions].

\section{V}

Abordo agora a adequação dos dois princípios em virtude da igualdade dos membros de uma sociedade bem-ordenada. Os princípios de igual liberdade e oportunidade equiitativa (parte b do segundo princípio) são uma expressão natural dessa igualdade; estou assumindo, portanto, que existe em tal sociedade alguma forma de democracia. Assim a nossa questão é: através de qual princípio os membros de uma sociedade democrática permitem que as tendências da estrutura básica sejam afetadas profundamente pelo acaso social e por contingências naturais e históricas? 
Ora, como estamos considerando os cidadãos como pessoas morais livres e iguais (a prioridade do primeiro princípio de igual liberdade dá expressão institucional a isso), o ponto de partida óbvio é supor que todos os outros bens primários sociais, e em particular proventos e riqueza, deviam ser iguais: todos deveriam ter uma partilha igual. Mas a sociedade deve levar em consideração as exigências organizacionais e a eficiência econômica. Assim não é razoável parar numa divisão igual. A estrutura básica devia permitir desigualdades, na medida em que estas melhorem a situação de todos, incluindo a dos menos favorecidos, desde que tais desigualdades sejam consistentes com a igual liberdade e a oportunidade eqüitativa. Pelo fato de começarmos de partilhas iguais, aqueles que são menos beneficiados têm, por assim dizer, um veto; e assim nós chegamos ao princípio da diferença. Ao tomar a igualdade como a base de comparação aqueles que ganharam mais devem fazê-lo em termos que são justificáveis para aqueles que ganharam menos.

Ao explicar esse princípio, várias questões devem ser lembradas. Antes de mais nada, ele se aplica, em primeira instância, aos principais princípios e políticas públicos que regulam as desigualdades sociais e econômicas. Ele é usado para ajustar o sistema de direitos essenciais [entitlements] e recompensas, assim como os padrões e preceitos que este sistema emprega. Assim, o princípio da diferença é válido, por exemplo, para provento e tributação de propriedade, para política fiscal e econômica; não se aplica a transações ou distribuições particulares, nem, de um modo geral, a decisões locais e de pequena escala, mas antes ao pano de fundo onde elas ocorrem. Nenhum padrão observável é exigido de distribuições efetivas, nem mesmo qualquer medida dos níveis de igualdade (tais como o coeficiente de Gini) que possam ser computados a partir destes. ${ }^{4} \mathrm{O}$ que se prescreve é que as desigualdades façam uma contribuição funcional aos menos favorecidos. Finalmente, o propósito não é eliminar as várias contingências, pois algumas dessas contingências parecem inevitáveis. Assim, mesmo que uma distribuição igual de recursos naturais parecesse em maior harmonia com a igualdade de pessoas livres, a questão da redistribuição de tais recursos (se fosse concebível) não se levanta, visto ser incompatível com a integridade das pessoas. Não precisamos tampouco fazer quaisquer suposições acerca da magnitude dessas variações; apenas supomos que, na medida em que são efetivadas em nossa vida mais tarde, elas são influenciadas pelos três tipos de contingências. A questão, portanto, é por qual critério uma sociedade democrática deve organizar a cooperação e regrar o sistema de direitos adquiridos (entitlements) que encoraja e recompensa esforços produtivos? Nós temos um direito a nossas aptidões naturais e um direito a qual-

${ }^{4}$ Para uma discussão acerca de tais medidas, ver A. K. Sen, On Economic Inequality (Oxford: Oxford Universidade Press, 1973), cap. 2. 
quer coisa para a qual sejamos habilitados [entitled to] por participarmos de um processo social eqüitativo. O problema é caracterizar esse processo. ${ }^{5}$

À primeira vista, pode parecer que o princípio da diferença seja arbitrariamente tendencioso com relação aos menos favorecidos. Mas suponha, por simplicidade, que há apenas dois grupos, um significantemente mais afortunado que o outro. A sociedade poderia maximizar as expectativas de qualquer grupo mas não de ambos, visto que podemos maximizar apenas com relação a um único propósito cada vez. Parece óbvio que a sociedade não deveria fazer o melhor que pode para aqueles que inicialmente são os mais favorecidos; assim, se rejeitarmos o princípio da diferença, devemos preferir maximizar alguma média ponderada [weighted mean] das duas expectativas. Mas como deveria essa média ponderada ser especificada? Deveria a sociedade proceder como se tivéssemos uma chance igual de estarmos em qualquer grupo (na proporção do seu tamanho) e determinar a média que maximiza esta expectativa puramente hipotética? Decerto é verdade que, muitas vezes, concordamos em sortear, mas normalmente apenas as coisas que não podemos dividir de maneira apropriada ou ainda as que não podemos desfrutar ou sofrer juntos. ${ }^{6} \mathrm{E}$ estamos dispostos a usar o princípio lotérico até mesmo em assuntos de importância duradoura, caso não haja nenhuma outra solução (considere o exemplo do recrutamento militar). Mas recorrer a tal princípio ao regular a própria estrutura básica seria extraordinário. Não há nenhuma necessidade para a sociedade, enquanto sistema duradouro, invocar o princípio lotérico nesse caso; nem há nenhuma razão para pessoas livres e iguais permitirem que suas relações, através de todo o curso de sua vida, sejam significantemente afetadas por contingências para uma maior vantagem daqueles que já foram favorecidos por esses acidentes. Ninguém tinha uma reivindicação anterior de ser beneficiado desse modo; e, portanto, maximizar um meio ponderado é, por assim falar, favorecer os mais afortunados uma segunda vez novamente. A sociedade pode, todavia, adotar o princípio da diferença para ordenar as desigualdades de tal modo que as contingências sociais e naturais sejam eficientemente usadas para beneficiar a todos, tomando a igual divisão como uma referência de avaliação de desempenho [benchmark]. Portanto, embora os recursos naturais não possam ser divididos de maneira uniforme, ou diretamente desfrutados ou padecidos em comum, os resultados de seus esforços produtivos podem ser alocados em modos consistentes com uma igualdade inicial. Aqueles favorecidos pelas contingências sociais e naturais se consideram já compensados, poder-se-ia dizer, pelas vantagens das quais ninguém (inclusive eles mesmos) fez uma reivindicação prévia. Assim eles conside-

\footnotetext{
A última parte desse parágrafo alude a algumas das objeções levantadas por Robert Nozick no seu livro Anarchy, State, and Utopia (New York: Basic Books, 1974), esp. p. 213-229.

- A esta altura, estou adaptando algumas observações de Hobbes. Ver Leviathan, cap. 15, sobre as décima terceira e décima quarta leis da natureza.
} 
ram o princípio da diferença apropriado para regular o sistema de direitos [entitlements] e desigualdades.

\section{VI}

A concepção de igualdade contida nos princípios de justiça foi por mim descrita como sendo kantiana. À guisa de conclusão, menciono rapidamente as razões para essa descrição. Claro, eu não quero dizer que tal concepção seja literalmente a concepção de Kant, mas antes que é uma das indubitavelmente inúmeras concepções suficientemente semelhantes às partes essenciais de sua doutrina que torna o adjetivo adequado. Muito depende do que é que se considera essencial. A visão de Kant é marcada por um número de dualismos, em particular, os dualismos entre o necessário e o contingente, forma e conteúdo, razão e desejo, número e fenômeno. Abandonar esses dualismos, como foram concebidos por Kant, é para muitos abandonar o que é distintivo em sua teoria. Eu sou de outra opinião. Sua concepção moral tem uma estrutura característica que é mais claramente discernível, quando esses dualismos não são tomados no sentido que ele lhes deu mas são reinterpretados e sua força moral reformulada dentro do escopo de uma teoria empírica. Um dos propósitos de Uma Teoria da Justiça foi indicar como esta seria feita.

A fim de sugerir a idéia principal, pense na noção de uma sociedade bemordenada como uma interpretação da idéia de um reino de fins concebida como uma sociedade humana sob circunstâncias de justiça. Ora, os membros de tal sociedade são livres e iguais, e nosso problema consiste, portanto, em achar uma interpretação de liberdade e igualdade que seja naturalmente descrita como kantiana; e visto que Kant distinguia entre liberdade positiva e negativa, devemos oportunizar esse contraste. A esta altura, recorro à idéia da posição original: eu supus que a concepção de justiça apropriada para uma sociedade bem-ordenada é aquela que seria acordada numa situação hipotética que fosse eqüitativa [fair] entre indivíduos concebidos como pessoas morais livres e iguais, isto é, como membros de tal sociedade. A eqüidade [fairness] das circunstâncias sob as quais o acordo é alcançado se transfere à eqüidade dos princípios acordados. A posição original foi concebida de tal forma que a concepção de justiça resultante seria apropriada.

Particularmente importantes, dentre as características da posição original para a interpretação da liberdade negativa, são os limites da informação, por mim denominados de "véu de ignorância" [veil of ignorance]. Ora, há uma forma mais forte e uma mais fraca desses limites. A mais fraca supõe que iniciemos com plena informação, ou com aquilo que possuímos na vida cotidiana, e então prossigamos para eliminar apenas a informação que levaria à parcialidade e propensão. A forma mais forte tem uma explicação kantiana: não iniciamos com informação alguma; pois Kant entende por liberdade negativa que somos capazes de agir independentemente da determinação de causas alheias; agir por necessidade 
natural é submeter-se à heteronomia da natureza. Interpretamos esta como requerendo que a concepção de justiça que regula a estrutura básica, com seus efeitos profundos e de longa duração em nossa vida comum, não deveria ser adotada por razões [grounds] que se embasam num conhecimento das contingências diversas. Assim, quando se concorda quanto a essa concepção, são excluídos o conhecimento de nossa posição social, nossos desejos e interesses peculiares ou de vários resultados e configurações de acidente natural e histórico. Permite-se apenas a informação requerida para um acordo racional. Isso significa que, na medida do possível, apenas as leis gerais da natureza sejam conhecidas juntamente com tais fatos particulares como são implicados nas circunstâncias da justiça. Obviamente, devemos capacitar as partes com alguma motivação, do contrário nenhum reconhecimento seria disponível. A discussão kantiana do segundo par de exemplos na Fundamentação indica, creio eu, que, ao aplicar o procedimento do imperativo categórico, Kant tacitamente se apoiou em algum registro de bens primários. Em todo caso, se os dois princípios fossem adotados na posição original com seus limites impostos sobre a informação, a concepção de igualdade que eles contêm seria kantiana, no sentido de que ao agir por essa concepção os membros da sociedade bem-ordenada exprimiriam sua liberdade negativa. Eles teriam logrado regular a estrutura básica e suas profundas conseqüências sobre as pessoas e relações mútuas por princípios cujos fundamentos [grounds] são adequadamente independentes do acaso e da contingência.

A fim de prover uma interpretação da liberdade positiva, duas coisas são necessárias: primeiro, que as partes concebidas como pessoas morais livres e iguais devem desempenhar um papel decisivo na sua adoção da concepção de justiça; e segundo, os princípios dessa concepção devem possuir um conteúdo apropriado para exprimir essa visão determinante de pessoas e devem ser aplicáveis ao objeto institucional de controle. Ora, se for correto, o argumento da posição original parece satisfazer essas condições. A suposição de que as partes são pessoas morais livres e iguais tem efetivamente um papel essencial neste argumento; e no que tange ao conteúdo e aplicação, esses princípios exprimem, na sua face pública como, se diria, a concepção das pessoas que é efetivada em uma sociedade bemordenada. Eles dão prioridade às liberdades fundamentais, consideram os indivíduos como entes livres e senhores responsáveis por seus propósitos e desejos, e todos devem compartilhar igualmente dos meios para a realização de fins, a menos que a situação de cada um possa ser melhorada, tomando a divisão igual como ponto de partida. Uma sociedade que efetivou esses princípios alcançaria a liberdade positiva, pois esses princípios refletem as características de pessoas que determinaram sua seleção e assim exprimem uma concepção que elas atribuem a si mesmas. 